J. Perinat. Med. $16(1988)$

\title{
The evolution and outcome of cavitating periventricular leukomalacia in infancy A study of 46 cases
}

\author{
David Shortland ${ }^{1}$, Malcolm I. Levene', John Trounce', ${ }^{2}$ in $\mathbf{~ N g}^{3}$, and Margaret \\ Graham $^{1}$
}

${ }^{1}$ The Departments of Child Health, Leicester University School of Medicine ${ }^{2}$, Nottingham City Hospital, and ${ }^{3}$ The Derby City Hospital, Great Britain

\section{Introduction}

Periventricular leukomalacia is a term first used by BANKER and LARROCHE in 1962 [1] to describe an abnormality of periventricular white matter recognized at post mortem in infants who die under one month of age. They implicated perinatal events in the pathogenesis of this lesion and recognized that it could cause later spastic cerebral palsy. None of the infants described in their original paper developed evidence of macroscopic cavitation within the white matter, but more recent pathological and ultrasonographic studies have found a significant incidence of extensive cavitating PVL. This change probably reflects the increased length of time that these critically ill infants survive which allows the natural history of this condition to evolve.

Recently a number of reports have been published documenting the frequency with which the condition is encountered $[11,15]$ and the outcome of affected infants $[2,3,6,7,8,17]$ but these studies have described relatively few infants. We have recently published follow up data on very low birth-weight (VLBW) infants with periventricular leukomalacia [9] but this is unrepresentative of the full spectrum of this condition. We report here data from 46 babies of all gestational ages in whom cavitating PVL was diagnosed using high resolution real-time ultrasound scans. This represents the largest group of infants to be reported to date and the incidence and significance of this condition is reviewed.

\section{Methods}

Regular, high quality real-time ultrasound scans have been regularly performed on infants admitted to two neonatal intensive care units at the Leicester Royal Infirmary and the Nottingham City Hospital. In these centres infants born at or below 32 weeks of gestation were routinely scanned with an ATL mark 600 sector scanner fitted with a 7.5 $\mathrm{MHz}$ transducer. Infants of more mature gestation were scanned only if they developed abnormal neurological features. Abnormal scans were recorded on video tape, hard copy X-ray or polaroid film.

\subsection{Definition}

The definition of cavitating periventricular leukomalacia (CPVL) was similar to that described by TrounCE et al, 1986 [15]. An echolucent area separate from the lateral ventricle was a pre-requisite for the diagnosis. Infants who developed echodensities in an area involving the ventricle and extending into the cerebral parenchyma, an appearance that has been previously defined as parenchymal haemorrhage [15], were excluded from this study.

\subsection{Incidence}

Infants below 32 weeks of gestational age were routinely scanned and it was therefore possible to estimate the incidence of CPVL. All infants who survived for 14 days or more, and who had at 
least one scan after this age were included. The incidence was calculated as the number of infants actually developing CPVL divided by the total number scanned after 14 days with or without CPVL for each week of gestational age.

\subsection{Timing}

In infants whose first early scan was normal, the time between the appearance of the initial echodensity and the first appearance of cavitation was recorded in order to study the sequence and timing of the ultrasound changes.

\subsection{Description}

The site of cystic degeneration was determined from the ultrasound records and was described in the manner suggested by BANKER and LARROCHE [1]. Three regions within the periventricular white matter were recognized; the anterior zone (anterior to the frontal horn of the lateral ventricle), the middle zone or centrum semiovale (lateral to the body of the lateral ventricles) and the posterior zone (adjacent and lateral to the occipital horns of the lateral ventricles). The maximum size of the cavitating lesion was described as small (less than $1 \mathrm{~cm}$ in diameter) or large $(1 \mathrm{~cm}$ or more in diameter).

\subsection{Follow-up data}

The infants were assessed either by a developmental paediatrician (Griffith's scales) or by their local paediatrician (Denver Developmental Scales). The infants were examined for evidence of cerebral palsy and visual impairement. If vision was thought to be abnormal, the infant was seen by a paediatric opthalmologist for further assessment. Infants of less than 6 months of age were considered to be abnormal if they showed marked hypertonus with hyper-reflexia. Comprehensive follow-up data is not available on all the infants at the present time and we have not included details of the development of the infants who had not reached a corrected age of three months.

\section{Results}

\subsection{Incidence of CPVL}

A total of 46 infants with CPVL were identified. Their gestational age ranged from 25 to 42 weeks (median 29 weeks). Birth weight ranged from 0.73

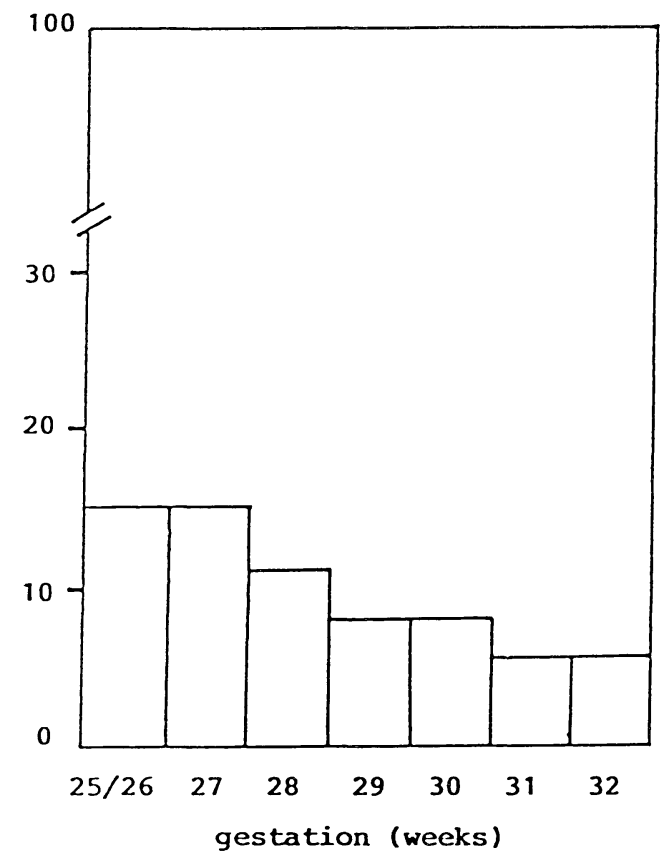

Figure 1. Proportion of premature infants developing CPVL by gestational age groups

$\mathrm{kg}$ to $3.6 \mathrm{~kg}$ (median $1.3 \mathrm{~kg}$ ). The greatest number of cases were seen in the most immature infants, but 6 babies developed cavities at 36 weeks gestation or more. The true incidence of CPVL in all infants at or below 32 weeks of gestation is shown in figure 1. These infants show an inverse relationship between the incidence of CPVL and advancing maturity. There is a $10 \%$ overall incidence of CPVL for infants of 32 weeks gestational age and below. The incidence is $15 \%$ for those infants born at or below 28 weeks of gestation.

\subsection{Timing}

Fifteen infants had a normal cranial ultrasound scan initially and subsequently developed the parenchymal changes that we associate with PVL. The median time between the development of these parenchymal changes and the appearance of echolucent cavities was 15 days (range $7-21$ days). In 19 infants parenchymal changes were present on the first scan and in the remainder the scans were performed too irregularly to allow accurate timing of the onset of cavities. 


\subsection{Description}

In six of the 46 infants a permanent record of the scan findings was not available and in these we were unable to confirm the recorded site of the cysts. Table I shows the distribution of cysts in the remaining 40 infants. 19 infants had cysts involving one zone only and in the remaining 21 infants, more than one zone was involved; the posterior zone being most frequently affected. Eleven had cavities in the right hemisphere, 9 in the left and 20 had bilateral changes. In 24 infants it was possible to estimate the size of the cavities. Eleven infants had small lesions and 13 had either large cavities or a combination of small and large cavities.

\subsection{Outcome}

Twelve infants died before reaching a corrected postnatal age of three months and a further 3 infants were too young at the time of the study to have had a meaningful developmental assessment. Four infants have been lost to follow-up. Followup information was available for the remaining 27 infants (table II). The median age of assessment was 12 months. Eighteen infants had an abnormal neurological examination with or without developmental delay.

Nine infants were thought to show no evidence of cerebral palsy. Eighteen infants had cerebral palsy or markedly abnormal limb tone. Ten infants had spastic quadriplegia, 4 had spastic diplegia, and 4 had hemiplegia (two involving the left and one the right side; 1 had a double hemiplegia). The position of the cavitating lesions in the infants with cerebral palsy is shown in table II.

Infants with involvement of more than one zone have a greater risk of developing cerebral palsy than infants in whom cavities are confined to only one zone. Involvement of the anterior or middle zone alone is associated with a low risk of cerebral palsy, but posterior zone involvement predicts an increased risk of spastic cerebral palsy.

Twenty two infants had detailed information on developmental outcome as well as permanent recordings of early ultrasound scans. Sixteen were found to be developmentally normal and 6 had significant developmental delay. Table II shows the regions involved in each of these infants. There is no clear relationship between the site of cavities and developmental outcome. No infant had developmental delay without cerebral palsy.

An assessment of the size of the cavities was available in 10 infants who had no evidence of cerebral palsy; eight had small and two had large cavities. In the 14 infants with abnormal patterns of limb tone only three had small cavities, and the other 11 all had large cavities.

Table I. Cavitating periventriculart leukomalacia: The localisation of cytes in the three regions

\begin{tabular}{lllllll}
\hline & \multicolumn{2}{l}{ Region } & & & & \\
\cline { 2 - 7 } & I & II & III & I, II and III & I and III & II and III \\
\hline Infants (40) & 6 & 6 & 7 & 11 & 4 & 6 \\
\hline
\end{tabular}

Region I = anterior zone $\quad$ Region II $=$ centrum semiovale $\quad$ Region III $=$ posterior zone

Table II. Cavitating periventricular leukomalacia - location of cysts and outcome

\begin{tabular}{|c|c|c|c|c|c|c|}
\hline \multirow[t]{2}{*}{ Outcome } & \multicolumn{6}{|c|}{ Region Involved } \\
\hline & $\bar{I}$ & II & III & I, II and III & I and II & II and III \\
\hline Cerebral palsy $(n=18)$ & 0 & 1 & 3 & 6 & 2 & 6 \\
\hline No cerebral palsy (9) & 4 & 3 & 1 & 1 & 0 & 0 \\
\hline $\mathrm{DQ}<70(\mathrm{n}=6)$ & 1 & 1 & 1 & 1 & 1 & 1 \\
\hline $\mathrm{DQ}<70(16)$ & 3 & 3 & 3 & 3 & 0 & 4 \\
\hline
\end{tabular}

Regional I = anterior zone

Regional II = centrum semiovale

Region III $=$ posterior zone 


\section{Discussion}

The association between perinatal events and the development of PVL has been recognized for over 25 years [1]. The vascular origin of these lesions has been stressed by DE REUCK [5] and TAKASHIMA and TANAKA [14] and more recently, WIGGLESWORTH and PAPE [18] have suggested that impaired cerebral blood flow is an important factor in the development of cerebral ischaemia in the periventricular white matter.

We have previously described the ultrasonic appearances of PVL $[11,15]$ and the progression of the lesion from echodensity to echolucent cavities. The echogenic stage is however open to a degree of subjective interpretation and for that reason we have chosen here to concentrate on the more definite ultrasonic appearances of CPVL.

Before high resolution cerebral ultrasonography became available it was only possible to estimate the incidence of this condition in infants coming to autopsy and BANKER and LARROCHE [1] found an incidence of $19 \%$ in infants of all birth weights who died aged less than one month. PVL can be accurately diagnosed in infants using real-time ultrasound $[12,16]$ and the incidence of CPVL in living infants of birth weight $<1500$ grams is reported to range between 7.5 to $9.5 \%[11,15]$.

In the present study we have shown that $15 \%$ of infants born between 25 and 27 weeks of gestation develop CPVL contrasting with an incidence of $6 \%$ in infants born at 32 weeks gestation (figure 1). The high incidence found in the least mature infants only refers to infants surviving long enough for cavities to develop. BANKER and LARROCHE [1] found that PVL invariably involved the anterior and posterior zones and less commonly affected the middle zone. Shuman and SeleDNiK [13] reported that the occipital zone was most often affected but that the middle zone was involved more frequently than the anterior zone. We have found that the occipital zone is most commonly involved, either alone or in association with other regions.

The time taken for cavitation to occur is poorly documented in the literature. LEVENE et al [11] published a report of five infants with CPVL and noted that the time taken for the cavities to appear after first noting periventricular echodensity was between 5 to 19 days. WeINDLING et al [17] reported eight infants with CPVL and found that the cavities took between two and seven weeks to appear (median three weeks). We consider that it is possible to estimate the time taken for cavitation to occur only in those infants in whom the timing of the initial parenchymal echodensities is accurately known. In these 15 infants the median time at which cavitation was seen was 15 days (range $7-21$ days).

The regions of the brain that are affected by CPVL are not "essential" to life and therefore this is often not a fatal condition. The importance of this condition is its propensity to procedure neurological handicap in the survivors. BANKER and LARROCHE [1] were the first to recognise that PVL was related to mental retardation and spasticity. The close proximity of the corticospinal tracts and optic radiation to the lateral wall of the ventricles explains the high incidence of CP (and to a lesser extent cortical blindness) found in infants with CPVL.

In a previously reported follow up study of 13 VLBW infants with cavitating PVL [9], we found that multiple cavities or cavities in the occipital region were strongly correlated with cerebral palsy. This study, which includes these 13 infants, together with 33 other infants, allows us to make a number of points concerning the prognostic significance of CPVL in infants of varying gestational ages. Perhaps surprisingly, the prognosis was not as bad as reported from previous studies of fewer numbers of infants $[2,6,17]$. Only 18 of the 27 infants $(67 \%)$ in whom good follow-up data was available had evidence of significant handicap. this may be an underestimate because less severe degrees of cerebral palsy may subsequently be diagnosed at an older age than the infants reported here. Nevertheless, it is unlikely that infants with severe handicap would be missed when assessed at a median age of 1 year.

Cavities involving the posterior and middle zones more accurately predict cerebral palsy than those occurring anteriorly, and lesions confined to the anterior region are not associated with significant handicap. It is also apparent that discrete involvement of a single zone only is not associated with adverse outcome. These findings are largely in agreement with those of FAWER et al [8] who reported the outcome of 26 survivors with PVL and those of Cooke [4] who found that the presence of cystic lesions, particularly when bilateral, were strongly predictive of developmental delay. In general, the more mature infants who developed CPVL had the worst outcome. 
Cyst size has been previously shown to be an accurate predictor of the extent of the neurological damage $[8,10]$ and we have confirmed this finding. In 11 infants the largest cyst was less than $1 \mathrm{~cm}$ in diameter and eight $(73 \%)$ of these infants had no evidence of cerebral palsy. In 13 infants at least one cyst was more than $1 \mathrm{~cm}$ in diameter and 11 $(85 \%)$ of these infants had evidence of cerebral palsy.

It is of interest that cavitation is very poorly associated with severe developmental delay. This is perhaps not surprising as the lesions are apparently confined to the periventricular white matter, with sparing of the cortex. It is noteworthy that the subcortical motor fibres of the periventricular white matter are situated in the region we have referred to as the middle zone, yet the majority of infants with cavities in this region do not develop cerebral palsy, and it is the posterior zone that is most associated with spasticity. It is difficult to resolve these facts on a neuroanatomical basis.

\section{Summary}

Forty six infants with the ultrasonic diagnosis of cavitating periventricular leukomalacia (CPVL) have been reviewed. Follow up examination results allow correlation between the ultrasound appearances and subsequent neurodevelopmental and neurological deficits. The highest incidence of this condition was found in infants at and below 27 weeks gestation, and occurred in $15 \%$ of very premature infants surviving 14 days or more. Cavities developed 15 days after the onset of periventricular echodensity (median time). Ventricular dilatation occurred in $24 \%$ of the infants who developed cavities. Follow up information was available in 27 infants and 18 of these $(67 \%)$ had significant neurodevelopmental handicap. The location of echolucent cavities were de-

scribed as involving anterior, middle or posterior cerebral zones or any combination of these. Cerebral palsy was closely related to the presence of cavities, but there was little association between cavities and developmental delay. Four factors were found to predict cerebral palsy: cavities within the occipital zone, the involvement of multiple regions of the brain, lesions greater than $1 \mathrm{~cm}$ in diameter and cavities associated with subcortical leukomalacia. Lesions confined to the anterior or middle zones were unlikely to be associated with significant handicap. The presence of cavities per se was not associated with a higher incidence of severe developmental delay.

Keywords: Cavitating periventricular leukomalacia, cerebral infarction.

\section{Zusammenfassung}

Entstehung und Folgen der periventrikulären Leukomalazie mit Höhlenbildung beim Kind

Wir berichten über 46 Kinder, bei denen ultrasonographisch eine periventrikuläre Leukomalazie mit Höhlenbildung diagnostiziert wurde. Durch Nachuntersuchungen wurden die Befunde im Ultraschall mit den sich einstellenden Entwicklungsverzögerungen und neurologischen Defiziten korreliert. Die Inzidenz war am höchsten bei Kindern mit 27 und weniger Schwangerschaftswochen; bei $15 \%$ dieser Frühgeborenen, die 14 Tage oder länger überlebten, ließ sich die o. g. Korrelation nachweisen.

Nach einem mittleren Zeitraum von 15 Tagen mit $\mathrm{Zu}$ nahme periventrikulärer Echos setzte die Höhlenbildung ein. $24 \%$ dieser Kinder wiesen auch Ventrikelerweiterungen auf. Nachuntersuchungen waren bei 27 Kindern möglich. Davon hatten $18(\cong 67 \%)$ signifikante neurologische Beeinträchtigungen. Bei der Lokalisation der Höhlen wurde angegeben, ob sie im vorderen, mittleren oder hinteren Anteil des Zerebrums darstellbar waren. Zerebral bedingte Lähmungen, nicht jedoch Entwicklungsverzögerungen, korrelierten eng mit Höhlenbildungen. 4 Punkte waren geeignet, um eine zerebral bedingte Lähmung vorauszusagen: Höhlen im Occipitallappen, Einbeziehung multipler Regionen im Gehirn, Läsionen mit mehr als $1 \mathrm{~cm}$ Durchmesser und Höhlen in Assoziation mit einer subkortikalen Malazie. Läsionen des vorderen und mittleren Hirnanteils führten nicht zu signifikanten Beeinträchtigungen. Höhlenbildungen per se waren nicht assoziiert mit einer höheren Inzidenz von schweren Entwicklungsverzögerungen.

Schlüsselwörter: Kindheit, neurologische Entwicklung, periventrikuläre Malazie mit Höhlenbildung, zerebraler Infarkt. 


\section{Résumé}

Evolution et devenir de la leucomalacie cavitaire periventriculaire dans l'enfance; etude de $\mathbf{4 6}$ cas

On a passé en revue quarante six enfants chez lesquels a été porté le diagnostic échographique de leucomalacie cavitaire périventriculaire (CPVL). Les résultats des examens au cours du suivi permettent une corrélation entre les images échographiques et les déficits neurodéveloppementaux et neurologiques consécutifs. L'incidence la plus élevé de cette pathologie est trouvée chez des enfants de 27 semaines de gestation ou moins, et elle survient chez $15 \%$ des grands prématurés qui survivent 14 jours ou plus.

Les cavités se développent 15 jours après l'apparition de la densité échographique péri-ventriculaire (temps moyen). Une dilatation ventriculaire apparait chez $24 \%$ des enfants qui développent des cavités. On a pu disposer d'informations sur le suivi chez 24 enfants et 18 d'entre eux ont présenté un handicap neurodéveloppemental significatif. La localisation des cavités échographiques a été décrite comme atteignant les zones cérébrales antérieures, médianes et postérieures ou toute association de celles-ci.

La paralysie cérébrale est étroitement liée à la présence de cavités mais il y a peu de relations entre la présence de cavités et un retard développemental. On a trouvé 4 facteurs prédictifs de paralysie cérébrale: La présence de cavités dans la zone occipitale, l'implication de régions cérébrales multiples, des lésions supérieures à $1 \mathrm{~cm}$ de diamètre et la présence de cavités avec leucomalacie souscorticale. Les lésions limitées aux zones antérieures et médianes, par contre, n'entrainent pas de handicap significatif.

La présence de cavités en elle-même ne s'accompagne pas d'une incidence plus élevée de retard developpemental sévère.

Mots-clés: Avenir neurodéveloppemental, enfance, infarctus cérébral, leucomalacie cavitaire périventriculaire.

Acknowledgements: We were very grateful to Prof. A. D. MiLner, Drs RutTeR, CuRnOCK and DodD for allowing us to include their patients in this study and for the co-operation of the nursing staff at the two hospitals. Drs SHORTLAND, TROUNCE and GRAHAM were supported by the Spastic's Society. $\mathrm{Dr} \mathrm{Ng}$ is supported by the Medical Research Council.

\section{References}

[1] BANKer BQ, JC LARRoche: Periventricular leukomalacia of infancy. Arch Neurol 7 (1962) 386

[2] Bozynski MEA, MN Nelson, TAS Matalon, DR Genaze, C Rosati-Skertich, PM Naughton, WA MEIER: Cavitating periventricular leukomalacia: incidence and short-term outcome in infants weighing $<1200$ grams at birth. Devel Med and Child Neurol 27 (1985) 572

[3] Calvert SA, EM Hoskins, KW Fong, SC ForSYTH: Periventricular leukomalacia: Ultrasonic diagnosis and neurological outcome. Acta Paed Scand 75 (1986) 489

[4] COOKE RW: Early and late cranial ultrasonographic appearances and outcome in very low birth infants. Arch Dis Child 62 (1987) 931

[5] De Reuck J: The human periventricular arterial blood supply and the anatomy of cerebral infarction. Europ Neurol 5 (1971) 321

[6] Dubowitz LMS, GM Bydder, J Mushin: Developmental sequence of periventricular leukomalacia, correlation of ultrasound, clinical and nuclear magnetic resonance functions. Arch Dis Child 60 (1985) 349

[7] Fawer CL, A Calame, MT Currer: Neurodevelopmental outcome at 12 months of age related to cerebral ultrasound appearances of high risk preterm infants. Early Human Devel 11 (1985) 123

[8] Fawer CL, P Diebold, A Calame: Periventricular leucomalacia and neurodevelopmental outcome in preterm infants. Arch Dis Child 62 (1987) 30

[9] Graham M, MI Levene, JQ Trounce, N Rutter: Prediction of cerebral palsy in VLBW infants: A prospective Ultrasound study. Lancet ii (1987) 593

[10] Graziani LJ, M Pasto, C Stanley, F Pidcock, H Desai, S Desai, P Branca, B GoldBerg: Neonatal neurosonographic correlates of cerebral palsy in preterm infants. Pediatrics 78 (1986) 88

[11] LeVENE MI, JS WigGLesworth, V Dubowitz: Hemorrhagic periventricular leukomalacia in the neonate: A real-time ultrasound study. Pediatrics 71 (1983) 794

[12] Nwaesi CG, Ke Payse, DJ Martin, LE Becker, CR FITZ: Periventricular infarction diagnosed by ultrasound: a post mortem correlation. J Ped 105 (1984) 106

[13] Shuman RM, LJ Selednik: Periventricular leukomalacia: on one year autopsy study. Arch Neurol 37 (1980) 231

[14] Takashima S, K TanaKa: Development of cerebrovascular architecture leukomalacia. Arch Neurol 35 (1978) 11 
[15] Trounce JQ, N Rutter, MI Levene: Periventricular leucomalacia and Intraventricular Haemorrhage in the Preterm neonate. Arch. Dis Child 61 (1986) 1196

[16] Trounce JQ, D Fagan, MI LeVene: Intraventricular haemorrhage and periventricular leucomalacia: ultrasound and autopsy correlation. Arch Dis Child 61 (1986) 1203

[17] Weindling AM, MJ Rocheford, SA Calvert, TF RoK, A WiLKINSON: Development of cerebral palsy after ultrasonographic detection of periventricular cysts in the newborn. Devel Med Child Neurol 27 (1985) 800
[18] Wigglesworth JS, KE PaPE: An integrated model for haemorrhage and ischaemic lesions in the newborn brain. Early Human Devel 2 (1978) 179

[19] Young RK, MJ Hernandez, SK YAGel: Selective reduction of blood flow to white matter during hypotension in newborn dogs: a possible mechanism of periventricular leukomalacia. Annals Neurol 12 (1982) 445-448.

Received February 1, 1988. Revised April 28, 1988. Accepted June 15, 1988.

D. Shortland, M. D., MIL

Neonatal Unit

Leicester Royal Infirmary

Leicester LE1 5WW., U.K. 